\title{
Getting on Top of Oneself: Comments on Self-Expression
}

\author{
M. G. F. Martin
}

Received: 30 November 2009 / Accepted: 1 December 2009 / Published online: 29 January 2010 (C) The Author(s) 2010. This article is published with open access at Springerlink.com

\begin{abstract}
This paper is a critical review of Mitchell Green's Self-Expression. The principal focus is on Green's contention that all expression is at route, a form of signalling by an agent or by some mechanism of the organism which has been evolutionary selected for signalling. Starting from the idea that in some but not all expression an agent seeks to express his or her self, I question the centrality of communication to the idea of expression.
\end{abstract}

Keywords Mitchell green · Expression · Emotion · Theory of mind · Communication

1. In Self-Expression Mitchell Green offers us an elegant, economical, and powerful theory of expression which reaches from a grimace or curled lip, through verbal behavior, to Mahler's Ninth and the Angel of the North. A seemingly diverse group of psychological phenomena and behaviors are brought under the discipline of a common purpose. From the revelation of affect in behavior and play, engaging in linguistic communication, letting others know how you really feel, to using artistic artifacts for the expression of emotion or mood, all of these are to be explained as examples of expression. Green sees expression as at root a mode of communication: one shows one's psychological state through either making it perceptible; showing that one is in that state; or showing how it feels. What unites all of this is the following thought: an agent engages in expression where she signals her subjective point of view.

In Green's picture of speaker-meaning we can both show things as well as show that something is the case. This contrasts with the narrower focus on speakermeaning found in the Gricean project which overemphasizes showing that, something closely associated with linguistic communication and the use of signs mediated through convention. According to Green, through utilizing biologically

\footnotetext{
M. G. F. Martin $(\bowtie)$

Department of Philosophy, University College London, Gower Street, London WC1E 6BT, England e-mail: michael.martin@ucl.ac.uk
}

\section{G. F. Martin}

Department of Philosophy, University of California, Berkeley, 314 Moses Hall,

University of California, Berkeley, CA 94720-2390, USA 
endowed mechanisms we can show others some of our psychological states; indeed they can literally become objects of sight. This too, for him, belongs within the domain of speaker-meaning. And when we express ourselves in this way, he suggests, we can press a demand on others to empathize with us in order that they come to our aid or at least better understand us. In turn the possibility of making a psychological state manifest through expression leads to an account of how we are to understand the ways in which the arts can be expressive: music or a picture may show us a particular feeling or a way of regarding the world. What initially appears to be a tangle of overlapping phenomena, are revealed as belonging to a central psychological kind.

For Green, expression is often about making a connection between our psychological states and other people; allowing these people to come to be acquainted with our feelings. The inputs to expression are psychological states which are introspectible, and its outcomes (when an audience takes up the expression) are either the showing of something, or the showing that something is so: either a showing of a psychological state to the audience, or the audience's being shown that one's thoughts or feelings are so. In many cases empathetic understanding involves being acquainted with the psychological state one comes to understand, either through perception of it, or indirectly through exhibiting to oneself a psychological state with the same qualities (or one with somewhat different qualities but which are at least analogous to those of the original object of concern).

There is ambition and elegance in the way in which these matters are connected together through a simple, but fruitful, picture of meaning and the initial conceit of taking expression itself to be a form of meaning. Moreover the style with which these diverse threads are bound together is also admirable: Green offers us a general picture which draws not only on philosophical reflections, but the results of psychology and other empirical sciences to give us a feel for how we should think of this aspect of the human mind. One gets the sense not only of a powerful prolegomenon to a theory of this particular phenomenon (or cluster of phenomena) but also a very forceful illustration of how philosophical progress in general can and ought to be made.

The requirements on a critic, however, involve raising questions about aspects of the project at hand, rather than taking up the invitation to explore the further consequences of the theory, or adopt the methodology itself in application to other puzzles about human nature. In this space I won't concentrate on the ingenious approach to meaning and communication, although there is much here to admire and explore. And unfortunately I won't have to space to raise questions about the application to aesthetics. So I'll just ask some questions about the underlying theory of mind in play. And even here, of necessity, I'll restrict my concerns.

For example, I find intriguing, but also puzzling, Green's suggestion that we perceive the emotions of others. He suggests that this a commonsensical thought. But I'm not sure ordinary opinion offers a verdict on the matter. We do say things like, 'I saw the hate in her eyes', 'I could see the contempt on his lips'. But I don't think that commits us to supposing that we perceive the emotions, as opposed to their expression, any more than saying that one sees his father in his face leads one to suppose that one sees the father when one sees the son. And what puzzles me as much, is what should turn for Green on whether we see others' emotions. But, as I said above, there is no room here to pursue it further. 
Instead I'll focus on what I take to be possibly a deeper disagreement about one of the boldest steps that Green makes: namely that we can see what unifies expression in terms of communication and signaling. The questions I raise are just that: questions about some of the assumptions in play in developing the picture. If that gives a skeptical air to what follows, then I must apologize in advance for it. I do not mean to be skeptical of the project as a whole: as I said above, Self-Expression offers us the very model of how we should advance boldly in exploring the human mind. The intent of this discussion is very much to underline quite what an achievement it is.

2. My starting point is a seemingly minor cavil about the title of the book, and so its self-advertisement. The book is called 'Self-Expression', yet the principal topic throughout is that of expression. Green does talk on occasion of someone's selfexpression, and defines it explicitly on p. 43, but in most contexts that is simply interchangeable with talk of expression without anything being lost. Certainly nowhere in the book is expression per se contrasted with self-expression.

Yet, one might think, in common parlance self-expression is a distinctive activity to be remarked on in contrast to the mere expression of the inner. When Madonna exhorted late twentieth century womankind to express themselves, she assumed that there was a distinctive activity in which they weren't engaging quite enough. Likewise when stale art critics complain of the Brit Art scene of the same period that there was rather too much self-expression going on, the criticism focuses on something narrower than just the possibility of expression that is forever present in the arts. What people say is a not entirely reliable guide to how we should construct theories, but both examples are at least suggestive of the thought that there is a point to contrasting self-expression with expression per se.

Now, this may invite puzzlement: How can expression fail to be self-expression? For, leaving aside cases of vicarious expression, one is only in a position to express one's own psychological states, so surely one couldn't express anyone else's psychological states. If self-expression is expressing the psychological states of self, then all expression must be self-expression. (By vicarious expression, I have in mind those cases where an agent is authorized or delegated to pass on expression, as when the herald expresses the king's contempt, or the captain at the door conveys the army's condolences to the grieving family left behind. These are counter-examples to the claim that all expression is self-expression, if taken by the letter, but they are not counter-examples to the spirit of it.)

The puzzlement arises from the assumption that the point of marking some expression as an example of self-expression is to indicate who it is whose psychological states are in question. But that is not the most natural way of understanding the intended contrast. Self-expression contrasts with expression more generally in that the object of expression is the self per se rather than just some emotional state, or some opinion. The possibility of contrasting self-expression with expression just suggests that we don't take all of expression to be a matter of expressing the self in this way.

Now two immediate responses on Green's behalf would suggest that this is a minor cavil. First, one may offer the riposte that even if we grant this observation, at worst, this shows that Green's theory is guilty of minor over-advertising. It may be true that it doesn't deal with one aspect of the theory of expression, but while that may be of some common moral interest, that doesn't show that it should be central to a theory of expression in general. Secondly, and perhaps even more forcefully, 
one can point out that the extension of the theory to cover self-expression in the sense indicated here would be a very minor addition. For self-expression may be taken just to be a particular instance of the act of showing an object, as opposed to showing that something is the case. Green focuses his account of showing of on revealing one's psychological states but in this case, what is to be shown is the self or, perhaps, some persona offered as the social surrogate of one's self. Along these lines, one may concede that there is room for discussion of exactly what object is to be shown and under what conditions it can be shown in the case of self-expression, but still insist that is less a task for the theory of expression than a theory of the social import of the idea of self.

In what follows I'll pursue a slightly more pessimistic reading of the state of play, however. What I'll argue is that the contrast between mere expression and selfexpression throws up some more serious questions about the more general phenomenon of expression as such. I shall question whether we should accept Green's central contention that what unites the various phenomena of expression is that they are all signals of what is within. In omitting to focus on the contrast between self-expression and expression, Green ignores the way in which it may be important to our view of an example of expression whether the agent him or herself is signaling the presence of a psychological state. In turn I'll suggest that expression includes both cases with signaling and cases without it. We can make sense of certain examples as being cases of expression without supposing that the agent signals anything by them, or even that they have any evolutionary function of signaling.

Green himself does admit that there are examples of involuntary expression. Still, the picture as a whole builds on the central case of an agent signaling something through expression. We extend from the agent's signaling to other cases of expression, on Green's theory, by recognizing the role that expression can have as a signal when it has been recruited to some evolutionary function. So purposive signaling is central to the picture of expression on offer, and that's why it is useful to look at Green's discussion of spontaneous smiles, and why in contrast to some other theorists he classifies them as voluntary. In defending the classification of them as involuntary, we'll lay the basis for the proposal that we might want to think of some expression as independent of the agent's will, and separate from any communicative import.

3. In chapter five Green takes issue with Paul Ekman's contention that facial expressions are involuntary (121ff). As Green himself acknowledges, his own theory employs a stipulated notion of the voluntary: a piece of behavior is to be counted as voluntary if it can be prevented at the time of onset (28). And his discussion of Ekman focuses on whether Ekman has given a conclusive reason for supposing facial expressions to be involuntary (presumably not in the stipulative sense that Green wishes to employ, but whatever prior notion we might have which the stipulation refines). I'm entirely in accord with Green that the specific features Ekman highlights for treating such facial expressions as the Duchenne smile as involuntary are inconclusive, but at the same time I find it quite natural to count these smiles among involuntary affective behaviors; and although the term 'involuntary' has become something of a state of art, I find Green's stipulation here rather unnatural.

My colleague Tom Pink offered me an anecdote to illustrate the point. In his family many years ago, there was an aged great-aunt beginning to suffer from 
dementia who was liable to utter unpleasantries. Now she was not without some control of this disposition: if she focused on the task of preventing herself from saying the unsayable, she could remain entirely presentable in public. However, she didn't always focus on that task, and words could just slip out. On at least one occasion, presented with a bouquet of flowers at a school opening by a small boy, she responded with a seraphic smile saying somewhat sotto voce, 'Dirty little boy! Dirty little boy!' Since she had some control over herself, even if she wasn't exercising it on this occasion, it looks as if on Green's account that her verbal activity counts as voluntary. At the same time, I am inclined to agree with Pink that we take her here to be talking involuntarily.

From the point of view of action theory that suggests Green's definition of the involuntary is just too narrow. Among our actions, we may be inclined to mark something as involuntary to indicate that we have been coerced in it. Among our behaviors, on the other hand, the point of contrasting involuntary movement from voluntary action is to distinguish what's an action from what's not: that is, what among our behaviors issues from the will. To accept Green's stipulation while maintaining this connotation, then, would be to say that there is no more to something's being a physical action of mine, nothing more to its issuing from my will, than that I could have prevented its onset. This seems to me too impoverished a conception of physical action, and bleaches out the point of drawing the distinction between mere behaviors and actions in the first place. That I can, with some effort, prevent my arm from shaking does not in itself show that when I cannot be bothered so to control my movements, the arm's shaking is voluntary, where that would mean something done by me.

Now of course Green is not particularly interested in the theory of action, and so it is open to him to claim that from the perspective of gaining a good overview of the topic of expression, his stipulation does well enough. And, indeed, I would grant that from the point of view of his theory, the question whether a Duchenne smile is voluntary or not is not particularly central. Green allows that there are involuntary expressions: a smile might, as a gasp often does, involuntarily signal the presence of a certain emotional state; this will be so where it has been recruited as a signal, and has a function to indicate something about the psychological circumstances of the organism. The main information to be picked up will be what the smile or gasp itself could convey on its own. One may add, of course, that an agent who allows such a natural signal to manifest itself, when they could have prevented it, indicates something through their lack of control (at least where the fact that they do not exercise control is itself also manifest): the audience can take up that the agent has a preparedness to be open. But the availability of this additional information would not seem to shift the primary import of the expression, that is, of indicating the signaled psychological state. So the significance of this primary signal would not seem to be affected by its classification as voluntary or involuntary. If we accept Green's wider commitments in his theory, his stipulation about the voluntary would seem to carry little or no cost.

All the same, if one has not already taken on board his theory of expression, one might be inclined to treat differently those cases where something is expressive of an inner state when an agent has no direct control over its production (whether they could or could not have suppressed the expression) from those cases where we 
construe the agent as managing the situation and setting about to express themselves in doing or saying something. In part what matters here is whether the theory of expression needs to be sensitive to when an agent is acting or manifesting their will. That question brings us back to self-expression, in the sense of expression of the self, and with it the importance of the active/passive distinction.

4. A familiar narrative since ancient times views the agent as somewhat at the mercy of his or her passions. Mastery of the self involves learning to control these passions. Taken to extremes, such pictures propose a total separation between the self and the passions which seek to dominate it. A common corrective story is liable to insist that the active self can really be nothing over and above the desires and other passions which may move the person to act. But this story too may go to extremes; and in its extreme form, where we conceive of the self as nothing but the bundle of passions, not even careful Scottish irony can make the corrective any more plausible than the picture it seeks to replace. And so one is as likely to find accounts of the relation between will and desire as attempting a balancing act between these two extremes: the self standing apart from all desire and acting so as to control their influence; the self as nothing more than the sum of one's desires. On the one hand, we are inclined to allow for some separation of the passions from the self, assimilating action involving them into properly willed behavior only where the agent identifies with, or otherwise controls, the action which flows from the passion in question. On the other hand, we recognize that any choice or exercise of control by an agent reflects something about his or her character, and so can indicate something about what they really want.

The two philosophical extremes, and the attempt to find a harmonious position between them reflects something of a puzzle we face in ordinary life of making sense of people around us, and the strategies or hypotheses we have concerning the role their emotions play in their actions. These different strategies reflect different assessments of what is expressive in an agent's behavior and what the significance of such expressive elements can be. For example, in one situation, we may be inclined to think that an agent is overwhelmed by their passions, giving in to anger or jealousy, and so think of their outburst as not really expressing their true self. In this case, we are ready to recognize a contrast between passions on the one hand and the agent on the other. But that is not to endorse the initial extreme picture of a total separation of these things: faced with someone who seems entirely in control, we might complain that not enough of what is really them is on display; everything is too controlled; too mannered. A healthy person, we may think, is someone who allows some of their unruly passions just to show themselves. Some of the differences among these contrasting evaluations may reflect persisting and deep differences in the way in which agents can monitor and control their affective states and related dispositions of behavior; but perhaps equally as notable is the way in which we are moved by cultural fashion. In certain moods we care more for the spontaneous and the animal in us; at other times the pure focus of control seems better to reflect our ideas of the dear self.

What matters for our current purposes, however, is the thought that we need to make a three-way division when looking at the behavior and general disposition of an agent. There are the actions of the agent seen as arising from his or her will, and these contrast with those aspects of behavior for which we take as responsible certain 
psychological forces within the agent but outside of the will. In addition to the role of will, and of other psychological forces, we must recognize the role of an agent's persona, that artifact they offer to the social world, and through which they engage and interact with other people. The last of these seems purely to belong to a world of signs: its reality being a matter of what is to be communicated or taken up by others. In the other two cases, we can make sense of something being there, and manifest to us, whether or not some agent wishes to communicate its presence or not.

These three elements give us three kinds of case: one in which we see the agent as responsible for the expressive aspect of their behavior, and thereby take them to be communicating something to us; one in which we see other psychological forces as revealing themselves, and take that to be expressive of some aspect of the agent, even if not something which is properly self-expression. Finally, the possibility in which an agent, concerned with letting too much unruly out becomes so selfcontrolled, that we see the behavior as purely intended as communicative, and in which we fail to find anything properly expressive of the agent's true self.

So the contrast between expression in general and self-expression in particular requires us to press the question whether the heart of expression is always a matter of what is purposively communicated, or whether we care so much about expression precisely because it makes manifest to us aspects of an individual's psyche which nothing is intending to communicate.

5. For Green the fundamental contrast between that discernible aspect of an individual's behavior or disposition which is expressive and that which is not is carried by the distinction between what is signaled and what is not. According to him, neither the bulging vein on an angry forehead nor the blushing of a bride are expressive of what is within (or, rather, need not be), because there is no reason to think either is a case of the organism signaling something to a potential audience. I'm not sure whether Green thinks of this as a division we would be inclined to accept anyway, independent of his theory, but it strikes me as a cost of his account. For it is entirely natural to treat the bulge and the blush as aspects of the expressive dimensions of mind. And if we shift our focus to that of an interpreter faced with the task of making sense of an agent and their stance towards the world, then we can see why these two should not be demoted. What the interpreter needs to know are the things which are counted as properly psychological origins of behavior. In addition, if the above morality tale is correct, they need to be sensitive to the question whether those psychological origins are identified with the agent or not.

For a number of years I was concerned that my roommate in graduate school would often show signs of anxiety: his hand shaking when he rolled a cigarette or held a cup of coffee. But eventually I came to realize that he just had incipient Parkinson's disease, and had a very mild apraxia (which in no way has become more severe in the last twenty years). The moment I realized that, I treated his movement differently, and it looked different to me. From one perspective, low firing rates in neural centers of motor control and an emotional state of anxiety are both just internal causes of behavior. But faced with the normal demands of making sense of the social world and the actors within it, we tend to treat the two very differently: the latter kind of cause we classify as a psychological or mental cause of behavior; something our social competence needs to keep track of; the former, we think of as purely mechanical. So perhaps what classifies together various overt physical 
behaviors as expressive is just that we do so treat them as what we must track when discerning the mind of an agent.

It does not seem to me that tracking mental causes in any obvious way reduces to a concern with whether an agent has attempted to communicate or display something or not. Obviously one way in which the emotions of an agent may get the better of them is through insisting on calling attention to themselves to any hapless passer-by. There is no more apt description of such manifestation than signaling, and Green is surely right to underline it. But what is more contentious is the idea that all expression should be some form of signaling. That I attribute his spiteful comment to his need for revenge is sufficient grounds for me to take his action to be an expression of his anger, I do not in addition need to suppose that he acts so as to let the world know that he is angry; be that a conscious intention, or an evolutionary selected function.

From this way of thinking, the bulge and the blush earn their keep as part of the expressive realm through being a key for the interpreter as a way in to the psychology of the subject interpreted. The route in matters much less than the object of concern: that in making sense of others we are concerned with their psychological aspects and the manner in which these are made manifest. Of course this is to take as given that we classify emotional states such as anxiety along with thoughts as among the properly mental, inner in the sense of belonging to the inner world, the mind, rather than inner in the sense of just falling within the skin, as a propensity to low firing rates may be.

For Green, the fundamental classification here is that of what belongs to the subjective point of view. And the expressive is connected to this by its possession of the functional role of signaling this subjective point of view. What I am suggesting here is both that our fundamental category of the psychological or mental is broader than the subjective point of view (the emotions which overwhelm me and reveal themselves to others need not belong to my point of view on the world), and that expression need only be thought of in terms of giving us access to the mental realm of another (though not necessarily by perceiving it). The emphasis on signaling or communication is also too restrictive.

In short, Green suggests that what matters for expression is what the organism can select for signaling. In contrast, the suggestion here is that what matters is what can be the object for others of the task of making sense of someone. From a developmental perspective the dispute is this: Are we focused on the specialist task of succeeding in communication, a competence of pragmatics, or the broader competence of simply making sense of other human beings? For all the elegance of Green's theory, I see no reason to restrict our understanding of expression to the former rather than the latter.

Acknowledgments These comments were originally prepared for a meeting at the 2009 Central APA. Many thanks to Mitchell Green for his comments on this material at the time, and to the audience of that session.

Open Access This article is distributed under the terms of the Creative Commons Attribution Noncommercial License which permits any noncommercial use, distribution, and reproduction in any medium, provided the original author(s) and source are credited. 